\title{
Asur Belgelerinde Kan Parası
}

\author{
Faruk Akyüz*
}

\section{$\ddot{O ̈}_{z}$}

Bu çalışma Eski ve Yeni Asur Dönemi belgelerinden iyi bilinen "kan parası" uygulaması hakkındadır. Orta Asur Kanununda yer almasa da Kan parasının Asur toplum yaşamında ve hukuk anlayışında önemli bir yer edindiği diğer dönem belgelerinden bilinmektedir. Kan parasının, öldürülen kimsenin yakınları tarafından kazanılan bir hak olduğu anlaşılmaktadır. Asur belgelerinde kan parası dāmu kelimesiyle ifade edilmiştir. Bahsi geçen kelime Eski Asur Döneminde her zaman fonetik olarak yazılmışken, Yeni Asur Dönemi belgelerinde ÚŠ/MÚD logogramıyla da ifade edilmiştir.

Anahtar Kelimeler: Kan parası, Eski Asur, Yeni Asur, hukuk, yasal uygulamalar

\section{Blood Money in the Assyrian Documents}

\begin{abstract}
This study is about the practice of "blood money", which is well known from Old Assyrian and Neo-Assyrian documents. Although it is not included in the Middle Assyrian Law Code, it is known from the other sources of the period that it has an important place in Assyrian social life and legal understanding. It is understood that the blood money is a right earned by the relatives of the murdered person. In the Assyrian documents, the blood money is expressed with the word damu. While the word in question was always written phonetically in the Old Assyrian period, it was also expressed in the documents of the Neo-Assyrian Period with the logogram ÚŠ/ MÚD.
\end{abstract}

Keywords: Blood money, Old Assyrian, Neo-Assyrian, law, legal practices.

* Dr. Öğretim Üyesi, Samsun Üniversitesi, İktisadi, İdari ve Sosyal Bilimler Fakültesi, Tarih Bölümü, Samsun/TÜRKIYE, faruk.akyuz@samsun.edu.tr ORCID: 0000-0003-1132-8653 DOI: $10.37879 /$ belleten.2020.887

Makale Gönderim Tarihi: 30.06.2019 - Makale Kabul Tarihi: 09.01.2020

Belleten, Aralık 2020, Cilt: 84/Sayı: 301; 887-906 


\section{Giriş}

Asur toplumunun hukuk anlayışı hakkında doğrudan bilgi veren kanun maddeleri yalnızca Orta Asur Döneminde (MÖ 1500-1000) karşımıza çıkmaktadır. ${ }^{1}$ Eski Asur (MÖ 2000-1500) ve Yeni Asur (MÖ 1000-612) olarak adlandırılan dönemlerde kanunname olarak adlandırabileceğimiz herhangi bir belge ele geçmemiştir. Eski Asur Döneminde Anadolu'ya ticaret amacıyla gelen Asurlu tüccarların kendi aralarındaki problemleri, kärum'lardaki mahkemelerde çözüme kavuşturduğu, yerli bir kimse ile bir Asurlu arasındaki hukuki sorunların ise genellikle yerel otoriteler tarafindan karara bağlandığı anlaşılmaktadır. ${ }^{2}$ Metinlerde geçen "dikili taşın hükmüne göre" anlamindaki "kìma awāt naruä"im" ifadesi de bahsi geçen ve Asur idaresi tarafindan oluşturulan yazıtta en azından ticaretle ilgili hukuki bağlayıcı kuralların kayıtlı olduğunu göstermektedir. ${ }^{3}$ Yeni Asur Dönemine ait belgeler bu dönemde standart bir hukuk anlayışı olduğunu gösterir. ${ }^{4}$ Ayrıca çeşitli Asur merkezlerinden bahsi geçen döneme ait çok sayıda mahkeme kaydı ele geçirilmiştir. ${ }^{5}$ Hem Eski Asur hem de Yeni Asur Dönemlerinde Asur toplumunda karşılaştı̆̆ımız dikkat çeken hukuki bir uygulama "kan parası"dır. Anadolu'nun en eski yazılı belgeleri olan Kültepe tabletlerinde Asurlu tüccarlarla ilgili "kan parası" hususu birçok defa kaydedilmiştir. Bu belgelerin bir kısmı 1998 yılında Salih Çeçen tarafından yayımlanmışır. ${ }^{6}$ Sonraki yıllarda yayımlanan Kültepe tabletleri içerisinde de "kan parası" hakkında yeni belgeler bulunmaktadır. Kültepe tabletlerinde bahsi geçen bu uygulama yaklaşık 13 asır sonra Yeni Asur Dönemi hukuki belgelerinde de karşımıza çıkmaktadır. Eski ve Yeni Asur Dönemi belgelerinde kan parası dāmu

1 Martha T. Roth, Law Collections from Mesopotamia and Asia Minor, Scholars Press, Atlanta, 1995. Kadriye Yalvaç - Mebrure, Tosun, Sumer, Babil, Asur Kanunlarn ve Ammi Saduqa Fermam, TTK Yayınları, Ankara 2002.

2 Sebahattin Bayram - Ömer Kahya, "Asur Ticaret Kolonileri Çağı'nda Anadolu'daki Hukuki Uygulamalar Üzerine Bazı Değerlendirmeler", Akademik Tarih ve Diussünce Dergisi, C 5 (17 Ek Özel Sayı), (2018), s. 78.

3 Hüseyin Sever, "Yeni Kültepe Tabletlerinde Geçen "Kīma awāt naru’āim" Tabiri ve Değerlendirilmesi”, Dil ve Tarih-Coğgafya Fakültesi Dergisi, 34/1-2 (1990), s. 256-65; Eski Asur Dönemindeki hukuki uygulamalar hakkında bk. T. Klitgaard Hertel, Old Assyrian Legal Practices, Law and Dispute in the Ancient Near East, (OAA 6, PIHANS 123), Leiden 2013; F. Mario Fales, "Assyrian Legal Traditions", A Companion to Assyria, Ed. E. Frahm, 2017, s. 407-10; Bayram - Kahya, agm., s. 75-92.

4 Fales, agm., s. 414-18.

5 Yeni Asur Dönemi yargısal belgeler ve bunlarla ilgili yorumlar için bk. Jass, Remko, Neo-Assyrian Fudicial Procedures, SAAS 5, 1996.

6 Çeçen, Salih, "Yeni Delillere Göre Kültepe'de Kan Parası", XXXIV. Uluslararası Assiriyoloji Kongresi, 6-10 Temmuz 1987 İstanbul, Bildiriler Ankara, (1998), s. 291-96. 
kelimesiyle ifade edilmiştir. Bahsi geçen kelime Eski Asur Döneminde her zaman fonetik olarak yazılmışken, Yeni Asur Dönemi belgelerinde ÚŠ/MÚD logogramıyla da ifade edilmiştir.

\section{Kültepe Tabletlerinde Kan Parası}

Kültepe Tabletleri'nde, Anadolu'da cinayete kurban giden bir Asurlunun yakınlarına kan parası ödeneceğine dair ifadeler yer almaktadır. Kan parası hakkındaki en önemli husus, bu uygulamanın Asur ile Anadolu krallıkları arasında yapılan antlaşmalarda yer almasıdır. Hukuki konuları içeren bu metinlerde dāmam šaqa $\overline{-}-$ lum/tadānum/kašādum (kan parası ödemek/vermek/almak) ifadelerini görüyoruz. ${ }^{7}$ Kültepe'de ele geçen iki antlaşma metninde, Anadolu'da öldürülen bir Asurlunun yakınlarına kan parası ödeneceği belirtilir. Antlaşma metinlerine göre Anadolu'da öldürülen bir Asurlunun kâtilinin Asurlular'a teslim edilecek ve bizzat Asurlular tarafindan ölümle cezalandırılacaktır. Kanišs şehri ile Asur arasında yapılan antlaşmada (Kt. 00/k 6) kan parası hususunda şu bilgiler yer almaktadır:

"Senin şehrinde veya ülkende bir Asurlu’nun kanı döküldüğünde (öldürüldüğünde) ve malı kaybolduğunda (yakınlarına) belirlenmiş miktarlardaki kan parası ödenecek; katil Asurlulara teslim edilecek ve o bizzat onlar tarafindan öldürülecektir. (Katilin) yerine başka birisi verilmeyecektir. Kayıp mal (yakınlarnna) iade edilecektir."”

Hahhum $^{9}$ ile Asur arasındaki anlaşmanın kaydedildiği (Kt. 00/k 10) belgenin kan parasıyla ilgili kısmı şöyledir:

"Hahhum'da, şehir dışında veya ülkenin herhangi bir yerinde bir Asurlu soyulur ve öldürülürse, kan parası ödenecek; katiller öldürülmeleri için Asurlulara teslim edilecek; kayı mal tam olarak ödenecektir."10

7 Bk. Salih Çeçen - Karl Hecker, "ina mātika eblum, Zu einem neuen Text zum Wegerecht in der Kültepe-Zeit", in: Alter Orient und Altes Testament 240 (Fs von Soden), Münster, (1995), s. 35-36; Çeçen agm., s. 291 vd.; Cahit, Günbattı, "Two Treaty Texts Found at Kultepe", in: Assyria and Beyond Studies Presented to Mogens Trolle Larsen, (2004), s. 254-55, 262.

8 Cahit Günbattı, "Kültepe'de Bulunmuş İki Antlaşma Metni”, Belleten C LXIX, (2005), s. 76166.

9 Eski Asur dönemi kaynaklarında Hahhum ile ilgili bilgiler ve Hahhum'un lokalizasyonu hakkındaki tüm görüşler ve değerlendirme için bk. İran Albayrak, "Eski Asurca Kaynaklara Göre Asur-Anadolu İlişkilerinde Hahhum Krallı̆̆ı'nın Önemi”, Archivum Anatolicum, 12/2, Ankara 2018, s. 1-11.

10 Günbattı, "Kültepe'de Bulunmuş İki”, s. 768-74. 
Anadolu'da cinayete kurban giden Asurlunun yakınlarına belirlenmiş miktarda kan parası ödenmesi; katilin Asurlulara teslim edilerek bizzat onlar tarafindan öldürülerek cezalandırılması gibi Asurlulara verilen önemli tavizler, yerli yönetimlerin yapılan ticaretten sağladıkları kazanç ve onların getirdikleri mallara duydukları ihtiyaçla açıklanabilir. ${ }^{11}$ Bir antlaşmanın devamı olduğu zannedilen Kt. n/k 794 env. numaralı bir metinde de "Eğer senin ülkende kanlı (cinayet) meydana gelirse, sen, katilleri öldürmemiz için bize teslim edeceksin" denilmektedir. ${ }^{12}$ Antlaşma metinlerinde kan parasının ödenmesine rağmen kısasa kısas uygulanarak katilin bizzat maktulün yakınları tarafindan öldürülmesi başka Asur belgelerinde görülmemektedir.

Kültepe tabletleri içerisinde "kan parası"nın bahis edildiği üç önemli olay mevcuttur. Bunların her biriyle ilgili birden fazla belgenin bulunması kan parası hakkındaki hukuki süreci ve maktulün yakınları tarafindan edinilen maddi kazanımları tespit etmeye imkân vermektedir. Antlaşma metinlerinde sözü edilen katilin Asurlulara teslim edilmesi ve onlar tarafindan öldürülmesi hakkında herhangi bir bilgi bulunmamaktadır. Bunun sebebi eldeki belgelerde kan parası davalarının Asurlular arasında geçmiş olmasıdır. Aşağıda incelenecek üç olay dışında Kt. 97/k 155 numaralı mektupta ${ }^{13}$ kan parasıyla ilgili st. 20-22'de "tabletlerim içinden biri senin kan paranla (ilgilidir)" ifadesi yer alır.

\section{Ennam-A'nın Kan Parasi}

Ennam-A'nın kan parasının konu edildiği dava 1949 yılı kazılarında ${ }^{14}$ ele geçirilen üç tablette geçmektedir. Bunlar kan parası ile ilgili sürecin tam anlamıyla takip edilebilmesine imkân vermektedir. İlk belge Asur şehir meclisinin kararının yer aldığ̣ waklum mektubudur. ${ }^{15}$ Tercümesi şöyledir:

11 Günbattı, "Kültepe'de Bulunmuş İki”, s. 778; Günbattı, Cahit, Kültepe-Kaniş, Anadolu’da İlk Yazı İlk Belgeler, Kayseri Büyükşehir Belediyesi Kültür Yayınları, Kayseri 2017, s. 137.

12 Çeçen - Hecker agm., s. 31-41.

13 Çayır, Murat, Kültepe’de 1997 Kilında Bulunan Tabletlerin Değerlendirilmesi, Ankara Üniversitesi Sosyal Bilimler Enstitüsü, Yayımlanmamış Doktora Tezi, 2012, no. 41.

14 Kültepe'de ilk sistemli kazılar 1948 yılında başlamıştır. Kültepe'deki ilk araştırmalar ve kazı tarihçesi için bk. Tahsin Özgüç, Kültepe, Kanišs/Neša, Yapı Kredi Yayınları, İstanbul, 2005, s. 8-9.

15 Asurlu tüccarların kendi aralarında yaşadıkları problemlerin çözümünde nihai karar mercii Asur şehir meclisi idi. Asur kralının başkanlığında toplanan mecliste alınan karar Kaniš kārum'una, tüccar ya da tüccarlara gönderilmekteydi. Bu belgelerde Asur kralı waklum unvanını kullanmaktaydı. Bk. Esma Öz, "Kültepe Kazılarında Ele Geçen Waklum Mektupları”, Uluslararası Sosyal Araştırmalar Dergisi, 4/16, (2011), s. 2. Waklum konusundaki diğer çalışmalar için bk. Salih Çeçen, "Kültepe Metinlerinde Bulunan Yeni Waklum Mektupları", Ankara Üniversitesi Dil ve Tarih-Coğrafya 
"Waklum Kaniş kārum’una şöyle der: 'şehir (meclisi) kararı hamrum’da verdi. Ennam-A’nın oğlu Aššur-rabi dava vekilini Kaniş’e gönderecek ve Ennam-A’nın oğluna kan parası ödenecek."”16

Diğer iki belgeden biri Asur şehrinde diğeri ise Kaniš’te düzenlenmiştir ve her iki belgenin içerikleri aynıdır. Illk kararın alındığı Asur şehrinde düzenlenen belgenin tercümesi şöyledir:

“Aššur-rabi’nin oğlu Ennam-A’nın kan parasılla ilgili şehrin tabletini Sū'e(n)-tata getirdi ve Ennam-Aššur ile meseleyi bitirip şehrin huzurunda yemin ettik. Babası Aššur-rabi’nin yerine Sū'e(n)-tata gümüşü aldı."17

Tabletler, niçin veya nasıl öldürüldüğü bilinmeyen Ennam-A’nın kan parası meselesinin çözüme kavuşturulduğunu göstermektedir. Asur şehir meclisinin aldığı karar tatbik edilmiş Asur'daki kararın yazılı olduğu belgeyi, öldürülen Ennam-A’nın torunu Sū'e(n)-tata Kaniš'e getirmiştir. Kâtil Ennam-Aššur ile aralarında belirtilmeyen bir miktar gümüş üzerinde anlaşarak kan parasını temizlemişlerdir.

\section{Aššur-nādā'nın Oğlunun Kan Parası}

Kültepe'den kan parası hakkındaki diğer bir örnek ise Aššur-nada hakkındadır. Aššur -nada muhtemelen Purušhattum'da meydana gelen isyanda öldürülmüştür. 1950 yılında kazılardan ele geçirilen iki belge konu hakkında detaylı bilgiler sağla-

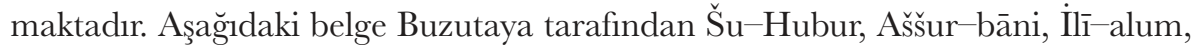
İ̌me-Aššur ve Aššur-emūqīye hitaben yazılmıştır. Mektupta şu ifadeler yer almaktadir:

“Šu-Hubur, Aššur-bāni, İli-alum, İšme-Aššur ve Aššur-emūqīye söyle. Buzutaya şöyle (söyler): Uşağımın ve Aššur-nādā'nın oğlunun cinayeti ile ilgili olarak Purušhattum kārum’unun tabletini ve şahitlerimin tabletlerini aldım ve tutuyorum. Cinayeti araştırdığım zaman [...] cinayet (olduğunu) ortaya çıkardım. [...] kārum'un [...] benim işittiğim onların $[\ldots]$ benim

Fakültesi Dergisi, XXXIV, (1990), s. 35-51; Cécile Michel, Correspondance Des Marchands De Kaniš Au Début Du IIe Millénaire Avant F.-C, Paris, 2001; Guido Kryszat, "Wer Schrieb Die Waklum-Briefe?”, in: Assyrian and Beyond. Studies Presented to Mogens Trolle Larsen, Leiden, (2004), s. 353-58.

16 Çeçen, "Kültepe Metinlerinde Bulunan”, s. 44; Çeçen, "Yeni Delillere Göre, s. 292 (Kt b/k 180).

17 Çeçen, agm., s. 293 (Kt. b/k 162/b). Kanišste düzenlenen belgenin tercümesi: "Aššur-rabi’nin oğlu Sü’e(n)-tata şehrin mektubunu getirdi. Kariya'nn oğlu Ennam-Aššr ile meseleyi halletti ve şehrin huzurunda meseleyi hallettik ve babası Aššrur-rabi'nin yerine Sü'e(n)-tata gümüşü aldl.” Bk. Çeçen, agm., s. 294 (Kt. b/k 162/a). 
için alın ve onların tabletini buraya yolla(yın). Şehrin tabletleri ile birlikte kaydedin ve tableti alın (ve) bana gönderin! Tabletimi bana gönderip, adamlara söz verin! İşitmiyor musunuz? Saray tahrip edilirken Şu-su'en’in oğlu Su'en-nādā, Kutubatani'nin oğlu Šumī-abiya, Kukubaza; 5 veya 6 (kişilik) bir grup öldürülmüşlerdir ve kime [...] verdiler [...]."18

Belgeden, ismi verilmeyen bir yerde, muhtemelen bir isyan neticesinde, sarayın tahrip edildiği ve bu sırada beş veya altı kişinin öldüğü anlaşılmaktadır. Ölenlerden üçünün ismi Buzutaya tarafindan bilinmektedir. Ölenlerden biri Buzutaya'nın uşağı diğeri ise Aššur-nada'nın oğlu olmalıdır. İkinci belgede ise Aššur-nada'nın oğlunun kan parasıyla ilgili, onun bir diğer oğlunun Asur şehir meclisine başvurduğu görülür. Bu hususta şehir meclisi aşağıda tercümesi verilen karara varmıştır:

“Buzutaya'ya söyle! Aššur-emūqī şöyle (söyler): Burada Aššur-nādā’’n oğlu şehir (meclisine) başvurdu. Şehir meclisinin önünde, hamrum'da konuştuk. Şehir (meclisi) kararı şöyle verdi: Buzutaya Kaniš’te Aššur’un hançeri önünde Aššur-nādā’nın oğlunun kan parası için gümüş almadığına ve kan (parasını) tutmadığına (dair) yemin edecek ve Ǎšsur-nādā’nın oğulları ve kızı (da) kan parası için Buzutaya'ya (hukuken) itiraz etmeyecekler. Bu tablet şehrin kararının kopyasıdır.”19

Tablet, meselenin öncesi hakkında detay vermez fakat belgenin içeriğinden Buzutaya'nın Aššur-nādā’nın oğlunun kan parasını almakla itham edildiği anlaşılır. Buna istinaden Buzutaya Aššrur'un hançeri önünde yemin edecek ve bu suretle Aššur-nādā'nın evlatları Buzutaya'ya hukuki itirazda bulunmayacaklardır. Asıl mesele Aššur-nādā'nın kan parasının temininden ziyade Buzutaya'nın kan parasını haksız biçimde alıp almadığıdır. Belki de Aššur-nādā’nın katili veya katilin yakınları kan parasını Buzutaya'ya ödediklerini iddia etmişlerdi. Bu sebeple önce Buzutaya ile ilgili meselenin çözümü ele alınmış ve Asur şehri yukarıda bahsedilen kararı almıştır. Kaniš’te Tanrı Aššur'un hançeri önünde yapılacak yemin sonrasında Aššur-nādā'nın yakınlarının kan parasının temizlenmesi için girişimde bulunacaklarını söyleyebiliriz. Meselenin ne şekilde sonuçlandığını bilinmemektedir. İlk tablette Buzutaya'nın uşağının ve Aššur-nādā'nın oğlunun ölümünden birlikte bahsedilmesi Buzutaya ile Aššur-nādā arasındaki yakın ilişkiyle alakalı olabilir. 
Belki de Buzutaya'ya, uşağının ve Aššur-nādā'nın oğlunun kan parası birlikte ödenmiştir. Öldürülen kişinin kan parasını başkasının alabildiği bir Asurlunun üç vatandaşına hitaben yazdığı bir mektuptaki, "Senin kardeşinin kan parasın biz aldık. (Bizden başka) hiç kimse kan parası alamadı." ifadesinden de anlaşılmaktadır. ${ }^{20}$

İlk belgede Anadolu'da adı bilinmeyen bir şehrin sarayında çıkan kargaşadan bahsedilmiştir. Bu isyanın hangi şehirde olduğunun bilinmediği yazarlar tarafindan ifade edilmiştir. ${ }^{21}$ Birçok belgeden Anadolu'nun çeşitli şehirlerinde bazı isyanların meydana geldiği bilinmektedir. ${ }^{22}$ Bahsi geçen kargaşa bu isyanlardan biriyle alakalı olabilir. 22 numaralı belgedeki "Purušhattum kārumu'nun tabletini ve şâhitlerimin tabletini aldım ve tutuyorum" ifadesi kargaşanın bu şehirde yaşandığına 1şık tutabilir. Ayrıca çiviyazılı belgelerden Purušhattum şehrinde birçok isyanın meydana geldiği de bilinmektedir. ${ }^{23}$ Aşağıda tercümesi verilen Kt. 94/k 775 numaralı belgede, Ennam-Aššur'un kan parasıyla ilgili olayın yaşandığı yer olan Tawniya şehrinin kralına başvurulmuştur. Yukarıdaki belgede yer alan "Purušhattum kārum'unun tabletini ve şahitlerimin tabletlerini aldrm ve tutuyorum" ifadesi isyanın bu şehirde yaşanmış olabileceğine dair önemli bir işarettir.

\section{Ennam-Aššur’un Kan Parasi}

Kültepe tabletlerinde "kan parası" hakkındaki önemli bir mesele ise ŠalimAššrur'un oğlu ${ }^{24}$ Ennam-Aššur’un ölümüyle ilgilidir. Birçok belgeden süreçle ilgili detaylar takip edilebilmektedir. Ennam-Aššur'un ölümü Enna-Suen’in mektubundaki “İtūr-il̄ ve Ali-ahum'a Enna-Suen şöyle söyler: Ennam-Aššur'un öldü-

20 Julius Lewy, Die Kultepetexte aus der Sammlung Frida Hahn, Berlin, Leipzig, 1930, s. 27.

21 KT 9-a s. 7.

22 Bk. Hakan Erol, "Kültepe'den Bir Metne Göre Asur Bölgesinde Yaşanan Bir İsyan ve Anadolu'daki Diğer İsyanlarla İlgili Kayıtlar", ArAn, 11/2, (2017), s. 23-38. Asur Ticaret Kolonileri Döneminde Anadolu'daki isyanlarla ilgili diğer çalışmalar için ayrıca bk. Salih Çeçen "Kültepe Belgelerine Göre Anadolu Şehir Devletlerinde Ayaklanma”, ArAn 5, (2002), s. 65-68; Remzi Kuzuoğlu, "Three Kültepe Texts Concerning Rebellions", Journal of Near Eastern Studies 70, (2011), s. 25-33.

23 Metinlerde Purušhattum ile ilgili isyan kayıtları şöyledir: KTH I, 1: 3-6; "Hem Purušhattum hem de Wahšušana'da ayaklanma olduğundan sizin olduğunuz yere Wahšušana’ya geçmedim.” KTS II 40 (BIN 4, 34): 27-30; "Purušhattum'da sulh hâkimdir. Ulana Purušhattum ile ittifak yaptr." KT 6-b 366: 6-10; "Bilgi için Purušhattum'a gönderilecek Aluwa ile ilgili olarak; Purušhattum'da isyan vardır." Kt m/k 13: 25-26; "Purušhattum'da isyan olduğu bilinmektedir. Bu yüzden oraya gidemedim." Ayrıca Kt n/k 1464: 25-29 ve $\mathrm{Kt} \mathrm{n} / \mathrm{k}$ 1251:12-17. satırlar da bir isyan ya da kargaşaya işaret etmektedir.

KT 6c 530: 4 (Kt 94/k 1454). 
ğünü duydum. ${ }^{25}$ ifadesinden anlaşılmaktadır. Ali-ahum mektubunda kärum temsilcisi Damiq-pī-Aššur'un tutumundan ve İtur-ilī’nin Tawniya kralına gönderdiği mektuptan bahsetmektedir. Ennam-Aššur'un ölümü için İtur-ilī’nin ona verdiği demiri sebep göstermekte, kārum'dan ümidini kesmesi sebebiyle Asur'da meclisin toplanı bir karar almasını beklemektedir:

"Sonra kārum Damiq-pī-Aššur'u haberci olarak gönderdi ve o kārum’un isteklerini reddetti ve İtur-ilī’nin isteklerini kabul etti. Damiq-pī-Aššur İtur-ilī’den Tawniya kralına götürdüğü mektubu kārum’un temsilcisi (olarak) okudu.... kardeşimin kan parasını tedarik etmediğinden ve iki yıldan beri (beni) babamın evinin gümüşü (hususunda) bana zorluk çıkardığından ve kardeşim onun demiri yüzünden öldürüldüğü için kız kardeşime ve kardeşimin kızına yardım et, şehir meclisine başvur ve yetenekli bir avukat edin." ${ }^{26}$

KT 6-c 527 numaralı belge Ennam-Aššur'un İtur-ilī’den aldığı demiri Tawniya Krallığında kralın kendisine satmayı başardığını göstermektedir. Bu ticaretten kısa süre sonra Ennam-Aššur soyguna uğramış ve öldürülmüş olmalıdır. ${ }^{27}$ Bir diğer belge ise Ali-Ahum tarafindan Kaniš kārum'una yazılmıştır. Belgenin ilk kısmında Tawniya kralıyla aralarındaki görüşme iletilmektedir:

"Temsilcilerinle kardeşimin kan parasını araştırmak için yola çıktık. Tawniya kralıyla görüş̧ük ve temsilciler şöyle dedi: 'bizim kardeşimiz senin bölgende öldü. Biz ve onun kardeşi senin babanız. Adamın kan parasını bizimle birlikte araştır." Kral cevapladı: '.. yaklaşılk 5 mina gümüş harca$\operatorname{dim} . . .{ }^{\prime 28}$

Mektubun devamında İtur-ìlī, Ali-Ahum ve kārum'un aralarında geçen konuşma yer almaktadır:

"Ben kendim ölümden kaçtım ve Kaniš'e güvenle vardım ve dedim ki: Benim kardeşim senin demirin yüzünden öldürüldü. La-qep adına aldığ1 gümüş, kesinlikle o senin verdiğin demirin (karşllı̆ğ) olan gümüş yüzünden öldürüldü. Git ve kardeşimin kan parası için araştır. Kārum ona sordu ve

\footnotetext{
25 KT 6c 523 (Kt. 94/k 830).

26 KT 6c 525 (Kt.94/k 775).

27 KT 6c s. 19.

28 KT 6c 527 (Kt.94/k 937: 1-13).
}

Belleten, Aralık 2020, Cilt: 84/Sayı: 301; 887-906 
dedi ki: Adam senin demirin yüzünden öldürüldü. Git ve onun kan parasını araştır. O cevapladı: Gitmeyeceğim adamın borcuna ait tabletim var”29

Tawniya Krallığına yapılan başvurular başarısız olmuştur. Hukuki sürecin işlemesi için yapılan girişimler İtur-ilī tarafindan engellenmiştir. Ennam-Aššur'un ölümünden üç yll geçmesine rağmen bir sonuç elde edilememiştir. Bir belgede İtur-ilī’nin girişimleriyle ilgili “Ennam-Aššur öleli üçyl oldu. Burada İtur-il̄̄ kārum'un kapısım aslan gibi kapatiyor. Adam için şâhitlik yapamuyoruz. ${ }^{930}$ ifadelerini kullanmaktadir.

İtur-ilī, Ennam-Aššur'un yakınlarının Asur şehrinde kan parası ve babalarının gümüşü için yaptığı girişimlerden haberdar olmuş ve Asur şehrindeki temsilcilerine ve Bēlum-bāni'ye onların girişimini engellemek için talimatlar vermiştir. ${ }^{31} \mathrm{KT}$ 6-c 530 numaralı belgeden katilin Asurlu olduğu düşünülmekte ve bu sebeple Tawniya kralı kendi uyruğundan olmayan birinin davası ile ilgili çaba sarf etmek istememektedir.

Kan parası meselesinde anlaşma metinlerinde Anadolulu birinin Asurlu birini öldürmesi durumunda çözüm bellidir. Fakat mesele Asurlular arasında geçince Ennam-Aššrur meselesinde olduğu gibi, güçlü kimsenin olayı kendi lehine kapatabilmesi mümkündür. Bu durumda Asur meclisinin kararının nihai karar olarak kabul edilmesi açısından oldukça önemliydi.

\section{Yeni Asurca Belgelerde Kan Parası}

Yeni Asur Döneminde az sayıda belgede kan parası hususuna rastlanmaktadır. Bunlar genellikle mahkeme kaydıdır. Aşağıda bu belgeler ve kan parası meselesinin nasıl çözüme kavuşturulduğu ele alınmıştır.

\section{Samāku'nun Kan Parası}

İlk satırları kırık olan belge muhtemelen Asurbanipal dönemine aittir. ${ }^{32}$ Bu belge, kan parasının ödenmemesi durumunda muhtemelen kırık kısımda ismi kaydedilmiş olan kâtilin, öldürülen kişinin mezarı üzerinde öldürüleceğini kaydeden

29 KT 6c 527 (Kt.94/k 937: 14-21).

30 KT 6c 528 (Kt.94/k 845:15-19).

31 KT 6c 529 ((Kt.94/k 1469).

32 Belgenin tarihleme kısmında limmu ismi kırıktır fakat devamında Asurbanipal'in ismi kayıtlıdır. SAA 14 125: r.1 "[...ynl, Asur] kra[lı] Asurbanipal." 
hukuki bir belge olması açısından ilginçtir. Belgenin tercümesi aşă̆ıdaki gibidir:

"Şimdi birlikte oldular (anlaştılar). O kan parası bedeli olarak kâtip Attar-qamu'nun kızı Kurra-Dimri’yi, Samāku'nun oğlu Šamaš-kenu-uṣur'a teslim edecek. (Böylece) O kanını temizleyecek. Ĕ̆er o kadını vermezse, onlar onu Samāku'nun mezarında öldürecek. Her kim anlaşmayı bozarsa 10 mina gümüş ödeyecek." ${ }^{33}$

Kan parası için herhangi bir miktar verilmemiş onun yerine bir köle verilmiştir. Belge ölüm cezası içermesi bakımından oldukça önem taşımaktadır ve Yeni Asur Dönemi yasal belgeleri içerisinde bu cezanın olduğu tek belge olarak bilinmektedir. $^{34}$

\section{Veliahdın Çobanının Kan Parası}

Yeni Asur belgeleri içerisinde kan parasıyla ilgili en dikkat çekici belge veliahdın çobanı ve koyunlarıyla ilgili hususu içeren MÖ 680 yılına tarihli tablettir. İlgili metnin çevirisi şöyledir:

“Sartinnu'nun (vezir) Hanî’ye yüklediği dava. Veliahdın 300 koyunu ve para cezası Hanî’ye yüklenmiştir. Çoban için kan parası 1 adam ve 2 talent bakırdır. Hanî, insanlarıyla (ailesiyle) ve tarlalarıyla birlikte, 300 koyun ve para cezasının ve çobanın kan parasının bedeli olarak alı konulmuştur.

Her kim onu araştırır. İster onun vâlisi ister onun birlik komutanı, ister onun yakını onu araştırır, 300 koyunu para cezasıyla ve çobanın kan parası bedeli olan bir adam ve 2 talent bakırı öderse Hanî serbest kalacak.

O nehir ordalini reddetti. ${ }^{\prime 35}$

Belge, veliahdın ${ }^{36}$ çobanını öldürmekle ve koyunlarını çalmakla suçlanan Hanî’nin suçlu olup olmadığının tespiti için nehir tanrısının adaletine başvurulmak istendi-

Kralın çocukları bir istisna hariç (SAA 6 103: 5 veliaht Arda-Mulissi) hiçbir zaman isimleriyle kaydedilmemiştir. mār-šarri ifadesi her zaman veliahdı (kralın oğlunu) ifade etmek için kullanılmıştır. mār-šarri ifadesi hakkında detaylı tartışma için bk. Simo Parpola, Letters from Asyrian Scholars to the Kings Esarhaddon and Assurbanipal II (AOAT 5/2, Neukirchen-Vluyn, 1983, s.173-174; SAA 6 s. xxvii-xxix. Tablet Asarhaddon'un tahta geçişinden 11 ay önceye tarihlidir. Bu sebeple belgede veliaht olarak kaydedilen kişi Asarhaddon olmalıdır.Bu konudaki tartışma için bk. SAA 6 dn. 264 (s. 212); Jass, age., dn. 51 (s. 11). 
ğini, fakat Hanî’nin nehir ordalini reddederek suçluluğunu kabullendiğini gösterir. Nehir ordali suçlamanın kanıtlanmasının çok zor olduğu yani şahit veya görgü tanıklarının bulunmadığı durumlarda başvurulan bir uygulamaydı. ${ }^{37}$ Nehir ordalinin özellikle tek bir sanık için uygulandığı, sanığın nehre dalıp öldüğü durumlarda herhangi bir mahkeme kaydının tutulmaya gerek olmadığı söylenebilir. Çünkü artık sanık ölmüş ve suçu sabitleşmiştir. Yeni Asur Dönemine ait böyle bir kaydın bulunmaması da bu durumu desteklemektedir. Burada nehir ordalinin asıl amacının cezalandırma değil suçun tespit edilmesi olduğunu belirtmek gerekir. ${ }^{38}$ Hanî örneğinde de görüleceği üzere sanığın nehir ordalini reddetmesiyle veya nehirden çıkamamasıyla suçlu olduğu tespit edilmiş oluyordu. Eğer nehirden çıkmış olursa da suçsuzluğu kesinleşiyordu.

Hanî’nin davasinda, nehir ordalini reddetmesiyle ona 300 koyun ve para cezası ile öldürdüğü adamın kan parası olarak bir adam ve 2 talent bakır yüklenmiştir. Hanî’nin bu cezayı ödeyecek gücünün olmaması sebebiyle de kendisi, ailesi ve tarlaları müsadere edilmiştir. Hanî ve ailesinin mahkemenin yüklediği ceza sebebiyle yani borç sebebiyle köle durumuna düştüğü söylenebilir. Bu durumdan tek kurtuluş yolu, Hanı̂’nin bir yöneticisi veya bir yakınının bahsi geçen cezayı ödemesidir.

\section{Silim-ili’nin Kan Parası}

“Öldürülen Silim-ili'nin bēl dāme'si Șirî. Onların (şehir halkı ve şahitler) huzurunda onun (Silim-ili’nin) eşi veya kardeşi veya oğlu ortaya çıarsa onlar (tablette mührü bulunanlar) kan parasinı ödeyecekler”39

MÖ 657 yllına tarihli bu belge Asurologlar arasında anlam açısından karmaşa yaratmıştır. Ölenin kim olduğu, "onlar" ifadesiyle kimin kastedildiği anlaşlamamıştır. R. Jass, çalışmasında Postgate ${ }^{40}$ ve M. T. Roth'un ${ }^{41}$ öldürülen kişinin Silimili olduğu görüşünü yanlış bularak A. Ugnad ve T. Kwasman’nn karşı görüşünü

37 Betina Faist, "The Ordeal in The Neo-Assyrian Legal Procedure" AOAT 412, Ugarit-Verlag, Münster, (2014), s. 197; Faruk Akyüz, "Asur Belgelerinde Nehir Ordali", OANNES - Uluslararası Eskiçă̆ Tarihi Araştırmalan Dergisi, 2/2, (2020), s. 168-75; bu uygulamada Nehir tanrısı yargilayıcı sıfatıyla ilahi hâkim görevini yerine getirmekteydi. Bk. Koray Toptaş - Ömer Kahya, Asurca ve Babilce Metinlerde Yemin", Türkiye Sosyal Araştırmalar Dergisi, 23/2, (2019), s. 320.

38 Faist, agm., s. 195.

39 SAA 1481.

40 J. Nicholas, Postgate, Fifty Neo-Assyrian Legal Documents, Warminster, 1976, s. 170-71.

41 Martha. T. Roth, "Homicide in the Neo-Assyrian Period", American Oriental Series, 67, (1987), s. 354. 
benimsemiştir. ${ }^{42} \mathrm{Bu}$ konudaki dayanağı ise tablette mührü bulunanlardan birinin Silim-ili olmasıdır. Bu tek başına yeterli bir kanıt değildir. Bazı tabletlerde aynı isme sahip farklı kişilerin mevcudiyeti bilinmektedir. ${ }^{43}$ Yeni Asur Dönemi şahıs adlarını içeren çalışmalarda Șirî’nin Silim-ili tarafından öldürüldüğü görüşü kabul edilmektedir. ${ }^{44}$ Tablette $b \bar{e} l$ dāme (kan davası hakkına sahip kimse/bir cinayet kurbanının yakın akrabası $)^{45}$ olarak Șirî’nin kaydedilmesi henüz bir yakınının orada olmayışından/ortaya çıkmamasından kaynaklandığı, belgenin 15-18. satırlarindaki "Onun (Silim-ilinin) eşi olsun, onun kardeşi olsun, onun oğlu olsun her kim ortaya çıkarsa" ifadesinden anlaşılmaktadır. Mishaly çalışmasında ${ }^{46}$ Șirî̀nin Samānu şehri tarafindan bēl dāme olarak, maktulün yakınlarının ortaya çıkması durumunda onlara verilecek kan parasının kefili olarak seçildiğini belirtir ki bu oldukça akla yatkındır. Belgede kan parasıyla ilgili herhangi bir miktar ifade edilmemiştir. Bu durum Asur toplumunda kan parası için belirlenmiş bir miktarın olmadığını ve cinayete kurban giden Silim-ili'nin ailesiyle anlaşlacak miktar üzerinden ödemenin gerçekleşeceğini gösterebilir.

\section{Bahçıvan Tamūzāiu'nun Kan Parası}

Bahçıvan Tamūzāiu'nun kan parası bahsinin geçtiği tablet bir köle satış belgesidir. ${ }^{47} \mathrm{Bu}$ hususla ilgili herhangi başka bir belge mevcut değildir. Sözleşmede Rāši-ili 30 šeqel karşılığında kölesi Attār-nūrı̄nnin Kusasu’ya satışını gerçekleştirmektedir. Belgenin 4'-6'. satırları arasında Attār-nūrī hakkında şu ifadeler yer almaktadır:

"Attār-nūrī, Sumuqiti şehrinden bahçıvan Tamūzāiu'nun kan parası yerine alınan (kimse)."

42 Jass, age., s. 63-4.

43 Bu hususa en yeni örneklerden biri Batman tabletidir. İlgili tabletin 4, 8 ve 9. satırlarında Ša-ilitazzaz ismiyle üç ayrı şahıs kaydedilmiștir. Bk. Koray Toptaş - Faruk Akyüz "A Neo-Assyrian Sale Contract from the Province of the Chief Cupbearer (rab-šaqê) kept at the Hasankeyf Museum (Batman)", Zeitschrift fir Assyriologie und Vorderasiatische Archäologie, 110/2, (2020), s. 1-9 PNA 1110 Nr. 8, 1177 no. 2.

45 Karen Radner, 2005. "The Reciprocal Relationship Between Judge and Society in the Neo-Assyrian Period", Maarav 12, (2005), s. 44; PNA 4/I 26b-27a.

46 Ayala Mishaly, "The Bēl Dāmē’s Role in the Neo-Assyrian Legal Process", Zeitschrift fuir Altorientalische Rechtsgeschichte 6, (2000) s. 45. Mihaly (2000:46) bēl dāme terimini iki taraf arasında ki anlaşma şartlarını belirleyecek kimse olarak ifade etmektedir. Bēl dāme ifadesi hakkında genel görüşler için bk. StAT 1 180-81.

47 Karlheinz Deller - F. Mario Fales - Liane, Jakob-Rost, "Neo-Assyrian Texts from Assur. Private Archives in the Vorderasiatisches Museum of Berlin, Part 2," SAAB 9/1-2 (1995), no. 77. 
Asurbanipal dönemine veya sonrasina tarihlenen belgeden Sumuquti şehrinde katledilen ve bahçıvan olduğu anlaşılan Tamūzāiu'nun kan parası yerine Attārnūrī köle olarak verilmiştir. Belge yoruma oldukça açıktır. Köle satış belgelerinde varsa kölenin mesleği ya da hangi şehirden oldukları gibi bilgiler kaydedilmiştir. Bahsi geçen metindeki gibi kölenin geçmişi hakkında bilgi içeren detaylarla karşılaşılmamaktadır. Attār-nūrı̄nnin kan parası yerine verilmiş olması iki durumu akla getirmektedir. İlki Attār-nūrī’nin özgür bir bireyken köle durumuna nasıl düşmüş olabileceğinin açıklanmış olması, diğeri ise Rāši-ili’nin ölen kişinin yakınlarından biri olduğu, kan parası yerine aldığı köleyi satarak kan parasını temin etmek istemesiyle alakalı olabilir.

\section{Nabû-šezib'in Kadınlarının Kan Parası}

Kahramanmaraş’ta bulunan Yeni Asurca belgeler içerisinde, MÖ 623 yllına ait bir mahkeme kaydında kan parasıyla ilgili ifadeye rastlanmaktadır. Belgenin tercümesi şöyledir:

Nabû-šezib'in, Siduni şehrinde Abda'a'nın evinden çıkartılmış olan, Nabûšezib'in kadınlarılyla ilgili işlediği suçla ilgili, Ubru-Nabû'nun Nabû'a'dan şikâyeti hakkındaki dâva:

Abda’a (şöyle) söyler: Sumusumusum'un arkasından Ubru-Nabû Marqasi şehrine geldi ve dâva açtı. Ubru-Nabû (dâvayı) doğruladı. Sonuçta kadınlarla ilgili bu dava çözülmüş (ve ölen kadın(lar) için) kan parası halledilmiştir. 10 šeqel gümüşü Nabû’a Ubru-Nabû'ya ödedi (ve) onlar aralarında anlaştllar. Her kim (daha sonra) itiraz ederse 10 mina gümüş ödeyecek. ${ }^{48}$

Belge Sidunu şehrinden Marqasi'ye getirilen kadınlar hakkındadır. Nabû-šezib’in Abda'a’nın evinden çıkarttı̆̆ı (aldı̆̆ı?) kadınlarla ilgili bir suç işlendiği belgede belirtilir. Mahkeme kaydında kan parasından bahsedilmesi kadınların en azından birinin öldüğünü göstermektedir. Kadın(lar)ın nasıl öldüğü veya öldürüldüğü kaydedilmemiştir. Suçu işleyen kişi Nabû-šezib olsa da dava edilen kişi Nabû'a'dır. Suç Siduni şehrinde işlenmiş fakat iki tarafin temsilcileri davayı Marqasi eyaletinde sonuca ulaştırmışlar ve bu dava sonucunda 10 šeqel kan parasına hükmedilmiştir. Düşük miktardaki kan parası kadın(lar)ın köle olduklarını düşündürmektedir.

$\mathrm{Bu}$ devre ait bir diğer belgede ise Niramayu şehrindeki 10 hektarlık bir tarlanın

48 Cahit Günbattı - Salih Çeçen - L. Gürkan Gökçek - Faruk Akyüz, Kahramanmaraş’ta Bulunmuş Yeni Asurca Tabletler, TTK Yayınları, Ankara 2020, Nr. 34: 1-14. 
Si’imme valisinin köleleri için "kan parası”nın yerine ayrıldığı anlaşılmaktadır. Belge kan parasına sebep olan cinayete ilişkin bilgi vermemektedir. ${ }^{49}$

\section{Sonuç}

Eski ve Yeni Asur Dönemlerinde görülen kan parası uygulamasında asıl amacın tazminat temini olduğu anlaşılmaktadır. Eski Asur Döneminde yerlilerin Asurlulara karşı işledikleri cinayet suçlarıyla ilgili hükümlerin kesinliği antlaşma metinlerinde kayıtlıdır. Fakat bu antlaşma maddelerinin tatbik edildiğini gösteren bir tabletle şimdiye kadar karşılaşılmamıştır. Eski Asur Dönemine ait yukarıda ele alınan metinlerdeki kan parası meseleleri Asurlular arasında geçmektedir. Bu belgelerden Asurlu tüccarların asıl amacının tazminat elde etmek olduğu görülmektedir. Eski Asur Dönemine ait antlaşma metinlerinde kan parasının ödenmesine rağmen kısasa kısas uygulanarak katilin bizzat maktulün yakınları tarafından öldürülmesi için Asurlulara teslim edileceğinin kaydedilmesi Yeni Asur Dönemindeki Samaku'nun kan parası hakkındaki belge ile kısmen benzerlik göstermektedir. Bahsi geçen belgede kan parası olarak kadının verilmemesi durumunda cinayeti işleyen kişi, ölen kişinin mezarı üzerinde öldürülecektir.

Eski Asur Döneminde Asurlu kimseler arasındaki kan parası hususunda asıl karar mercii Asur şehir meclisidir. Burada alınan kararlar nihai kabul edilmekte ve uygulanmaktaydı. Kan parasını sadece cinayete kurban gidenin yakınları değil onların adına başkaları da alabilmekte ve asıl sahiplerine ulaştırmaları beklenmekteydi. Ayrıca kan parasının başkaları tarafindan da ödenebildiği 'Ennam-Aššrur'un adına, Zaniwata'nın kanmın masrafı olan parayı, o ödedi ${ }^{{ }^{50} 0}$ ifadesinden bilinmektedir.

Yeni Asurca belgelerdeki kan parası uygulaması hakkındaki bilgilerimiz Eski Asur Dönemine kıyasla daha azdır. Bu dönemde saray erkânı tarafindan yapılan yargılamalarda ${ }^{51}$ alınan kararlar uygulanmaktaydı. Kan parası sadece gümüşle değil bakırla da ödenebilmekteydi. Kan parası, ölen kişinin yerine bazen sadece köle vermek suretiyle bazen de bir kişi ve bir miktar para şeklinde ödenmekteydi. Belirlenen kan parasının ödenememesi durumunda katilin mallarına el konularak kendisi ve ailesi köle durumuna düşmekteydi. Kan parasının ödenmemesi ya da

49 SAA 11 222: 1-3.

50 Çeçen, age., s. 295 (Kt. b/k 258/b).

51 Yeni Asur Döneminde yargılamaları yapanlarla ilgili detaylı bilgi için bk. Radner, agm., Table.1, s. $50-4$. 
mahkemede varılan antlaşmaya sonradan itiraz edilmesi durumunda da bir miktar para cezası uygulanabilmekteydi.

Yeni Asur Dönemi belgelerinde görülen bèl-dāme ifadesi, kan davası hakkına sahip kimse/bir cinayet kurbanının yakın akrabası olarak kabul edilmektedir. Bu kimse öldürülen yakını için dava açma ve kan parası talep etme hakkına sâhip idi. Bu ifade Yeni Asur Döneminde iki belgede görülmektedir. İlk belge tartışmalı olmakla birlikte öldürülen kimse için şehir tarafindan Șirî bēl dāme olarak görevlendirilmiştir. Oldukça kırık ve içeriği çok iyi anlaşılamayan SAA 21144 numaralı diğer belgede ise Utumu bēl dāme olarak kaydedilmiştir. 


\section{KAYNAKLAR}

Akyüz, Faruk, "Yeni Asur Döneminde Anadolu'da Kölelik ve Köle Satışları" Anadolu'nun Eski Çağlarnda Iktisadi ve Zirai Hayat, Editörler, L. G. Gökçek - O. Pekşen - E. Yıldırım, İstanbul, 2018, s. 399-411.

Akyüz, Faruk, "Asur Belgelerinde Nehir Ordali", OANNES - Uluslararası Eskiçă̆ Tarihi Araştırmalan Dergisi, 2/2, 2020, s. 165-177.

Albayrak, İrfan, "Eski Asurca Kaynaklara Göre Asur-Anadolu İlişkilerinde Hahhum Krallığı'nın Önemi”, Archioum Anatolicum, 12/2, Ankara 2018, s. 1-11.

Baker, Heather D., Prosopography of the Neo-Assyrian Empire, Vol. 3/I, Helsinki, 2002.

Baker, Heather D., Neo-Assyrian Specialists, Crafts, Offices, and other Professional Designations. The Prosopography of the Neo-Assyrian Empire, 4/I: Proffesions Index. Winona Lake 2017.

Bayram, Sebahattin - Kahya, Ömer, "Asur Ticaret Kolonileri Çağı'nda Anadolu'daki Hukuki Uygulamalar Üzerine Bazı Değerlendirmeler”, Akademik Tarih ve Düşünce Dergisi, 5 (17 Ek Özel Sayı), (2018), s. 75-92.

Çayır, Murat, Kültepe'de 1997 Yilında Bulunan Tabletlerin Değerlendirilmesi, Ankara Üniversitesi Sosyal Bilimler Enstitüsü, Yayımlanmamış Doktora Tezi, 2012.

Çeçen, Salih, "Kültepe Metinlerinde Bulunan Yeni Waklum Mektupları", Ankara Üniversitesi Dil ve Tarih-Coğrafya Fakültesi Dergisi, XXXIV, (1990), s. 35-51.

Çeçen, Salih, "Yeni Delillere Göre Kültepe'de Kan Parasi”, XXXIV. Uluslararası Assiriyoloji Kongresi, 6-10 Temmuz 1987 Istanbul, Bildiriler Ankara, (1998), s. $291-296$.

Çeçen, Salih, "Kültepe Belgelerine Göre Anadolu Şehir Devletlerinde Ayaklanma," ArAn 5, (2002), s. 65-68.

Çeçen, Salih, - Hecker, Karl, "ina mātīka eblum, Zu einem neuen Text zum Wegerecht in der Kültepe-Zeit", Alter Orient und Altes Testament 240 (Fs von Soden) içinde, Münster, (1995), s. 31-41.

Deller, Karlheinz - Fales, F. Mario -Jakob-Rost, Liane, "Neo-Assyrian Texts from Assur. Prívate Archives in the Vorderasiatisches Museum of Berlin, Part 2," SAAB 9/1-2 (1995), s. 3-137.

Erol, Hakan, “Kültepe’den Bir Metne Göre Asur Bölgesinde Yaşanan Bir İsyan ve Anadolu'daki Diğger İsyanlarla İlgili Kayıtlar”, ArAn, 11/2, (2017), s. 23-38. 
Faist, Betina, "The Ordeal in The Neo-Assyrian Legal Procedure" AOAT 412 , Ugarit-Verlag, Münster, (2014), s. 189-200.

Fales, F. Mario, "Assyrian Legal Traditions", A Companion to Assyria, Ed. E. Frahm, 2017, s. 398-422.

Fales, F. Mario - Postgate, J. Nicholas, Imperial Administrative Records, Part II, Provincial and Military Administration. SAA 11, Helsinki, 1995.

Günbattı, Cahit, "Kültepe'de Bulunmuş İki Antlaşma Metni”, Belleten C LXIX, (2005), s. 759-784.

Günbattı, Cahit, "Two Treaty Texts Found at Kultepe", Assyria and Beyond Studies Presented to Mogens Trolle Larsen, (2004), s. 249-268.

Günbattı, Cahit, Kültepe, Kaniš, Anadolu'da İlk Yazı, İlk Belgeler, Kayseri Büyükşehir Belediyesi Kültür Yayınları, Kayseri 2017.

Günbattı, Cahit - Çeçen Salih - Gökçek, L. Gürkan - Akyüz, Faruk, Kahramanmaraş’ta Bulunmuş Yeni Asurca Tabletler, TTK Yayınları, Ankara 2020.

Hertel, T. Klitgaard, Old Assyrian Legal Practices, Law and Dispute in the Ancient Near East, (OAA 6, PIHANS 123), Leiden 2013.

Jass, Remko, Neo-Assyrian Fudicial Procedures, SAAS 5, Helsinki 1996.

Kryszat, Guido, "Wer Schrieb Die Waklum-Briefe?", Leiden: Assyrian and Beyond. Studies Presented to Mogens Trolle Larsen, (2004), s. 353-358.

KT 6-b: Larsen, Mogens Trolle, Kültepe Tabletleri VI-b, The Archive of the ŠalimAššur Family Volume 2: Ennam-Aššur, TTKY, Ankara 2013.

KT 6-c: Larsen, Mogens Trolle, Kültepe Tabletleri VI-c, The Archive of the ŚalimAššr Family Volum 3: Ali-ahum, TTK, Ankara 2014.

KT 9-a: Albayrak, İran - Erol, Hakan, Kültepe Tabletleri IX-a, I. Cilt: Buzutaya ve Lipit-İstar Arşivleri, 1950 Fil Tabletlerinden (Kt. c/k) Seçilmiş Metinler, TTK, Ankara 2016.

Kuzuoğlu, Remzi, "Three Kültepe Texts Concerning Rebellions", fournal of Near Eastern Studies 70, (2011), s. 25-33.

Kwasman, Theodore, Legal Transactions of the Royal Court of Nineveh, Part I: Dated and Datable Texts. SAA 6, Helsinki 1991. 
Lewy, Julius, Die Kultepetexte aus der Sammlung Frida Hahn, Berlin, Leipzig 1930.

Mattila, Raija, Legal Transactions of the Royal Court of Nineveh, Part II: Assur-banipal through Sîn-̌́arru-iškun. SAA 14, Helsinki 2002.

Michel, Cécile, Correspondance Des Marchands De Kaniš Au Début Du IIe Millénaire Avant f.-C, Paris 2001.

Mishaly, Ayala, "The Bēl Dāmē’s Role in the Neo-Assyrian Legal Process", Zeitschrift fiur Altorientalische Rechtsgeschichte 6, (2000) s. 35-53.

Öz, Esma, "Kültepe Kazılarında Ele Geçen Waklum Mektupları", Uluslararası Sosyal Arasttrmalar Dergisi 4/16, (2011), s. 1-11.

Özgüç, Tahsin, Kültepe, Kanišr/Neša, Yapı Kredi Yayınları, İstanbul, 2005.

Parpola, Simo, Letters from Assyrian Scholars to the Kings Esarhaddon and Assurbanipal II (AOAT 5/2), Neukirchen-Vluyn 1983.

Parpola, Simo, The Correspondence of Assurbanipal, Part I: Letters from Assyria, Babylonia, and Vassal States. SAA 21, Helsinki 2018.

Postgate, J. Nicholas, Fifty Neo-Assyrian Legal Documents, Warminster 1976.

Roth, Martha T., "Homicide in the Neo-Assyrian Period", American Oriental Series 67, (1987), s. 351-65.

Roth, Martha T., Law Collections from Mesopotamia and Asia Minor, Scholars Press, Atlanta 1995.

Radner, Karen, "The Reciprocal Relationship Between Judge and Society in the Neo-Assyrian Period", Maarav 12, 2005, s. 41-68.

Sever, Hüseyin, "Yeni Kültepe Tabletlerinde Geçen "Kīma awāt naru'āim” Tabiri ve Değerlendirilmesi”, Dil ve Tarih-Coğrafya Fakültesi Dergisi 34/1-2 (1990), s. 251-265.

StAT 1: Radner, Karen, Ein neuassyrisches Privatarchiv der Tempelgoldschmiede von Assur. (Studien zu den Assur-Texten 1), Saarbrücken 1999.

Toptaş, Koray - Akyüz, Faruk, "A Neo-Assyrian Sale Contract from the Province of the Chief Cupbearer (rab-šaqê) kept at the Hasankeyf Museum (Batman)", Zeitschrift fuir Assyriologie und Vorderasiatische Archäologie, 110/2, 2020, s. $1-9$.

Belleten, Aralık 2020, Cilt: 84/Sayı: 301; 887-906 
Toptaş, Koray -Kahya, Ömer, "Asurca ve Babilce Metinlerde Yemin” Türkiye Sosyal Araştırmalar Dergisi, 23/2, 2019, s. 315-330.

Yalvaç, Kadriye - Tosun, Mebrure, Sumer, Babil, Asur Kanunlan ve Ammi Saduqa Fermanı, TTK Yayınları, Ankara 2002. 
